\title{
CRESCIMENTO INICIAL DE MUDAS DE Bombacopsis glabra (Pasq.) A. Robyns SOB CONDIÇÃO DE SOMBREAMENTO ${ }^{1}$
}

\author{
Silvana de Paula Quintão Scalon², Rosilda Mara Mussury², Marilúcia Rossi Rigoni ${ }^{3}$ e Homero Scalon Filho²
}

\begin{abstract}
RESUMO - Este experimento foi desenvolvido com o objetivo de estudar o crescimento de mudas de Bombacopsis glabra (Pasq.) A. Robyns (castanha-do-maranhão) sob diferentes intensidades luminosas. A capacidade de emergência das plântulas foi determinada pela porcentagem e pelo índice de velocidade de emergência, utilizando quatro repetições de 100 sementes ( 1 semente/saco). Após 40 dias, 75 mudas foram transferidas para condições de 30 e $50 \%$ de sombreamento e para pleno sol. O desenvolvimento das mudas foi conduzido em delineamento de blocos casualizados, com três repetições de cinco mudas, nas quais foram avaliados a altura do caule e o diâmetro do colo aos 61, 82, 103 e 124 dias após a emergência das plântulas; o teor de clorofila a, b, total e a razão a/b; a massa seca da planta (MS); a área foliar (AF); a taxa de crescimento relativo (TCR); a razão de área foliar (RAF); a taxa assimilatória líquida (TAL); e a sobrevivência aos 103 e 124 dias após a emergência, quando o experimento foi encerrado. As sementes apresentaram $95 \%$ de emergência e alto de índice de velocidade de emergência $(1,7)$. As mudas apresentaram 100\% de sobrevivência em todos os tratamentos. Os níveis de luz estudados não afetaram a sobrevivência das mudas, o diâmetro do caule, a área foliar, a clorofila a e b, a TCR, a TAL e a RAF, nos intervalos de tempo estudados. As mudas crescidas sob 50\% de sombra apresentaram maior altura, maior clorofila total e menor relação a/b. A castanha-do-maranhão é uma espécie de fácil propagação, apresentando bom desenvolvimento das mudas sob pleno sol e tolerando o sombreamento de 30 e $50 \%$.
\end{abstract}

Palavras- chave: Bombacopsis glabra, emergência, sombreamento e crescimento.

\section{INITIAL GROWTH OF Bombacopsis glabra (Pasq.) A. Robyns SEEDLINGS UNDER SHADING CONDITIONS}

\begin{abstract}
This experiment was carried out to study the growth of Bombacopsis glabra (Pasq.) A. Robyns seedlings under different light intensities. The germination capacity of the seeds was determined by the index and percentage of germination speed of a hundred seeds (1 seed/sac). After 40 days, seventy-five saplings were transferred to 50\% and 30\% shade and beds under direct sunlight. Sapling development was carried out in randomized block design with three repetitions of five saplings, with stem height and lap diameter being evaluated on the $61^{\text {st }}, 82^{\text {nd }}, 103^{\text {rd }}$ and $124^{\text {th }}$ day after sapling emergence. Chlorophyll content $a, b$, total and ratio a/b; dry mass of the plant $(D M)$, leaf area $(L A)$, relative growth rate $(R G R)$, leaf area rate $(L A R)$ and net assimilating rate $(N A R)$ and survival sapling percentage were measured on the $103^{\text {rd }}$ and $124^{\text {th }}$ days, when the experiment was concluded. The seeds presented 95\% of germination and a high index of germination speed (1.7). The saplings presented $100 \%$ of survival in all the treatments. Shade levels did not affect sapling survival, stem diameter, leaf area, chlorophyll a and b, RGR, LR and LAR during the studied intervals. The saplings grown under 50\% shadow presented a higher height, larger concentration of total chlorophyll and a lower a/b ratio. Bombacopsis glabra propagates easily, presenting a good development at full sunlight and enduring $30 \%$ and $50 \%$ shade.
\end{abstract}

Key words: Bombacopsis glabra (Pasq.) A. Robyns, germination, shading, growth.

1 Recebido para publicação em 24.4.2002.

Aceito para publicação em 4.11.2003.

2 Professores do Centro Universitário da Grande Dourados (UNIGRAN) <silvana@unigran.br>. ${ }^{3}$ Acadêmica do Curso de Ciências Biológicas da UNIGRAN, Rua Balbina de Matos 2121, 79824-900 Dourados-MS, Brasil. 


\section{INTRODUÇÃO}

A exploração desordenada dos recursos naturais tem gerado a degradação de áreas em quase todo o território nacional (Ferreira, 2000). Várias pesquisas sobre a propagação, a emergência e o desenvolvimento de plantas nativas têm sido realizadas no Brasil. Entretanto, não foram encontrados na literatura estudos sobre a Bombacopsis glabra (Pasq.) A. Rob, espécie nativa ocorrente no Estado de Mato Grosso do Sul.

A castanha-do-maranhão é uma espécie ornamental arbórea da família Bombacaceae, que mede de 4 a $6 \mathrm{~m}$ de altura. Sua madeira é muito leve e mole, podendo ser usada para confecção de objetos leves como caixotes, réguas e brinquedos. Sua inflorescência é de coloração branca e cada fruto produz, em média, 20 sementes, que apresentam 100\% de germinação, ocorrendo de cinco a dez dias após semeadura (Lorenzi, 1998).

A utilização de espécies nativas para recuperação de áreas degradadas ou perturbadas tem crescido. O estudo da luminosidade é fundamental para a avaliação do potencial dessas espécies em programas de revegetação, pois a disponibilidade de luz constitui um dos fatores críticos para o seu desenvolvimento (Gajego et al., 2001). Em virtude da carência de conhecimentos, os estudos básicos para produção de mudas são de extrema importância para o desenvolvimento da atividade florestal e para programas de conservação (Monteiro \& Ramos, 1997).

Scalon \& Alvarenga (1993), em sua revisão sobre árvores nativas, observaram que geralmente há grande diversidade de respostas das plantas à luminosidade, principalmente quanto ao desenvolvimento vegetativo da parte aérea e à sobrevivência das mudas. Desta forma, a eficiência do crescimento da planta pode ser relacionada à habilidade de adaptação das plântulas às condições luminosas do ambiente. $\mathrm{O}$ crescimento satisfatório de algumas espécies em ambientes com diferentes disponibilidades luminosas pode ser atribuído à capacidade de ajustar, eficaz e rapidamente, seu comportamento fisiológico para maximizar a aquisição de recursos nesse ambiente (Dias-Filho, 1997).

Gajego et al. (2001) constataram que alguns estudos evidenciam um desenvolvimento mais favorável em condições de alta luminosidade para espécies heliófitas com maior produção de matéria seca (Sesbania sesban L.), enquanto em outros encontraram maior acúmulo de matéria seca em baixa luminosidade

R. Árvore, Viçosa-MG, v.27, n.6, p.753-758, 2003
(Muntingia calabura L.). Estudos de crescimento e respostas fotossintéticas para sombra em um grupo de plantas jovens tolerantes, moderadamente tolerantes e intolerantes à sombra mostraram que a biomassa total foi menor e a área foliar específica maior em condições de 79 e $89 \%$ de sombra (Groninger et al., 1996).

Freqüentemente as análises do crescimento de mudas são utilizadas para predizer o grau de tolerância das diferentes espécies ao sombreamento. Acredita-se que as espécies tolerantes apresentam um crescimento mais lento em relação às não-tolerantes, devido às suas taxas metabólicas mais baixas (Grime, 1965, 1977). O rápido crescimento em altura quando sombreadas é um mecanismo de adaptação das plantas competitivas (Grime, 1977) ou nômades (Tinoco \& Vasques-Yanes, 1985), como forma de escape ao déficit de luz, já que estas não são capazes de tolerar baixas intensidades luminosas através do reajuste de suas taxas metabólicas.

Um dos fatores ligados à eficiência fotossintética de plantas e, conseqüentemente, ao crescimento e à adaptabilidade a diversos ambientes é o conteúdo de clorofila e carotenóides. Além da concentração total desses pigmentos, a proporção entre eles e entre as clorofilas a e b muda em função da intensidade luminosa. Geralmente, a clorofila e os carotenóides tendem a aumentar com a redução da intensidade luminosa (Ferraz \& Silva, 2001; Fontes \& Silva, 2000). Entretanto, Engel \& Poggiani (1991) encontraram diferenças para algumas espécies.

O objetivo deste trabalho foi estudar o crescimento inicial de mudas de Bombacopsis glabra sob diferentes intensidades luminosas.

\section{MATERIAL E MÉTODOS}

O experimento foi realizado em 1999, em DouradosMS. A cidade está situada a $22^{\circ} 13^{\prime} 16^{\prime \prime}$ de latitude sul e $54^{\circ} 48^{\prime} 2$ " de longitude oeste e tem altitude de $452 \mathrm{~m}$. O clima é classificado como Cwa e a precipitação média anual é de $1.500 \mathrm{~mm}$, com temperatura média anual de $22{ }^{\circ} \mathrm{C}$.

As sementes de Bombacopsis glabra (Pasq.) A. Rob. (castanha-do-maranhão) foram coletadas em Dourados, diretamente no chão, e levadas para o laboratório de Botânica do Centro Universitário da Grande Dourados UNIGRAN, onde passaram por um processo de desinfecção com hipoclorito de sódio $1 \%$, por 10 minutos (Brasil, 1993). 
Na casa de vegetação da UNIGRAN, a semeadura ocorreu em sacos plásticos, contendo como substrato areia e solo (1:2) adubado com NPK (4-14-8, $2 \mathrm{~kg} / \mathrm{m}^{3}$ de solo). A capacidade de emergência das plântulas foi determinada pelo índice de velocidade e pela porcentagem de emergência (Popinigs, 1985), utilizando quatro repetições de 100 sementes (1 semente/saco).

Após 40 dias da semeadura as mudas foram transferidas para as condições de sombrites, equivalentes a 30 e $50 \%$ de sombreamento, e para pleno sol, recebendo 15 mudas cada um, totalizando 45 mudas. Os sombrites foram colocados em armação de madeira a $1 \mathrm{~m}$ de altura, de forma que as laterais também apresentassem sombrite. $\mathrm{O}$ ensaio de desenvolvimento da muda foi conduzido em delineamento de blocos casualizados, com três repetições, sendo cada parcela constituída de cinco mudas. As quatro avaliações de altura do caule e do diâmetro do colo foram realizadas aos 0, 61, 82, 103 e 124 dias após a emergência da plântula.

Para as demais avaliações, outras 15 mudas para cada condição de luminosidade foram utilizadas aos 103 e 124 dias após a emergência, totalizando 30 mudas. A medição de área foliar foi realizada com auxílio de integrador de área foliar "Li Cor." A dosagem da clorofila total, a e b e da razão $\mathbf{a} / \mathbf{b}$ foi realizada segundo metodologia de Arnon (1949). A razão de área foliar (RAF), taxa assimilatória líquida (TAL) e taxa de crescimento relativo (TCR) e massa seca da muda (MS) foram calculadas segundo Benincasa (1988).

A porcentagem de sobrevivência das mudas foi avaliada com base no número de mudas no início e ao final no experimento.

Os resultados foram submetidos à análise de variância e as médias comparadas pelo teste de Tukey, a $5 \%$ de probabilidade.

\section{RESULTADOS E DISCUSSÃO}

As sementes de castanha-do-maranhão apresentam alta porcentagem e velocidade de emergência (95\% e 1,7 respectivamente). Aos seis dias após a semeadura já se observava alta porcentagem de emergência, dados semelhantes aos observados na literatura (Lorenzi, 1998).

As mudas apresentaram 100\% de sobrevivência durante os testes de sombreamento.

Não houve interação significativa entre a idade da muda e os níveis de sombreamento para as variáveis altura do caule e diâmetro do colo (Figura 1a, b).
A altura das mudas variou aos 61 dias e 124 dias, não havendo diferença significativa nas idades de $82 \mathrm{e}$ 103 dias após a emergência. Quanto à disponibilidade da luz, as mudas apresentaram diferença significativa apenas para altura do caule, sendo maior sob 50\% de sombreamento, seguida de $30 \%$ e em pleno sol (Quadro 1).

O diâmetro do colo não variou significativamente entre os tratamentos luminosos e a idade da muda, sendo a média apresentada para o período avaliado de $1,7 \mathrm{~mm}$. Resultados semelhantes foram observados por Gajego et al. (2001) para mudas de pau-amarelo (Maclura tinctoria) e jatobá (Hymenae coubaril), enquanto Felfili et al. (1999), trabalhando com velame (Sclerolobium paniculatum), observaram que as maiores médias de diâmetro do colo ocorreram nos tratamentos em pleno sol.
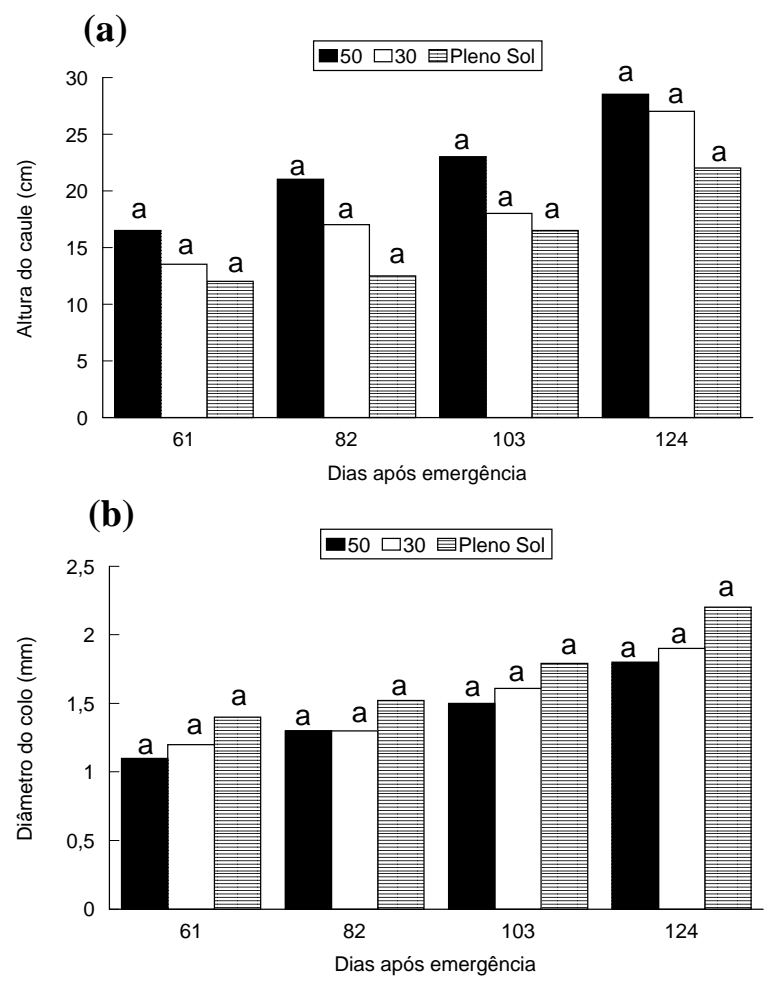

Figura 1 - Altura do caule (cm) e diâmetro do colo $(\mathrm{mm})$ das mudas de Bombacopsis glabra (Pasq.) A. Robyns (castanha-do-maranhão) crescendo em diferentes condições de luminosidade e dias após a emergência. UNIGRAN, Dourados-MS.

Figure 1 - Stem height $(\mathrm{cm})$, stem diameter $(\mathrm{mm})$ of Bombacopsis glabra (Pasq.) A. Robyns (castanha-domaranhão) saplings, under different Iuminosity conditions and days after emergence. Unigran, DouradosMS.

R. Árvore, Viçosa-MG, v.27, n.6, p.753-758, 2003 
Quadro 1 - Altura (cm) e diâmetro do colo (mm) de mudas de Bombacopsis glabra (Pasq.) A. Robyns em diferentes idades e condições de luminosidade (castanha-do-maranhão). Unigran, Dourados-MS

Table 1 - Stem height $(\mathrm{cm})$, stem diameter $(\mathrm{mm})$ of Bombacopsis glabra (Pasq.) A. Robyns (castanha-domaranhão) saplings, under different luminosity conditions. Unigran, Dourados-MS

\begin{tabular}{|c|c|c|}
\hline Tratamento & $\begin{array}{c}\text { Altura } \\
(\mathrm{cm})\end{array}$ & $\begin{array}{c}\text { Diâmetro } \\
(\mathrm{mm})\end{array}$ \\
\hline Idade da Muda & & \\
\hline 61 & $14,0 \mathrm{c}$ & $1,5 \mathrm{a}$ \\
82 & $16,8 \mathrm{~b}$ & $1,4 \mathrm{a}$ \\
103 & $19,2 \mathrm{~b}$ & $2,1 \mathrm{a}$ \\
124 & $25,8 \mathrm{a}$ & $2,0 \mathrm{a}$ \\
\hline Sombreamento & & \\
\hline Pleno sol & $15,8 \mathrm{c}$ & $1,83 \mathrm{a}$ \\
30 & $18,9 \mathrm{~b}$ & $1,58 \mathrm{a}$ \\
50 & $22,3 \mathrm{a}$ & $1,42 \mathrm{a}$ \\
\hline
\end{tabular}

Médias seguidas de mesma letra minúscula na coluna são estatisticamente iguais entre si pelo teste de Tukey, a 5\%.

Os valores de área foliar, RAF, TAL e TCR (Figura 2a , b, c e d) encontram-se na faixa de 220,83$170,62 \mathrm{dm}^{2} ; 4,75-4,35 \mathrm{dm}^{2} \mathrm{x} \mathrm{g}^{-1} ; 3,4-1,75 \mathrm{~g} \mathrm{x} \mathrm{dm}^{2} \mathrm{x}$ dia; e $13,5-5 \mathrm{gxg}^{-1} \mathrm{x}$ dia. Embora não tenha sido detectada diferença significativa entre os tratamentos luminosos, a área foliar e a TCR (Figura 2a e b), nas mudas cultivadas em pleno sol, apresentaram valores 23 e $63 \%$ superiores aos das mudas cultivadas sob $50 \%$ de sombreamento. O aumento da área foliar nos seis primeiros meses de desenvolvimento da planta mostra a habilidade da espécie em utilizar a radiação fotossinteticamente ativa e alocar os fotoassimilados em resposta a um ambiente particular de luminosidade (Dias-Filho, 1997). Assim, a área foliar pode ser considerada um índice de produtividade, dada à importância dos órgãos fotossintetizantes na produção biológica.

As mudas crescidas em pleno sol apresentaram maior massa seca da parte aérea que as de outros tratamentos. A massa seca das mudas foi inversamente proporcional ao sombreamento (Quadro 2). Felfili et al. (1999) demonstraram que mesmo espécies tolerantes ao sombreamento alcançam a máxima produção de massa seca quando crescem em pleno sol.

R. Árvore, Viçosa-MG, v.27, n.6, p.753-758, 2003
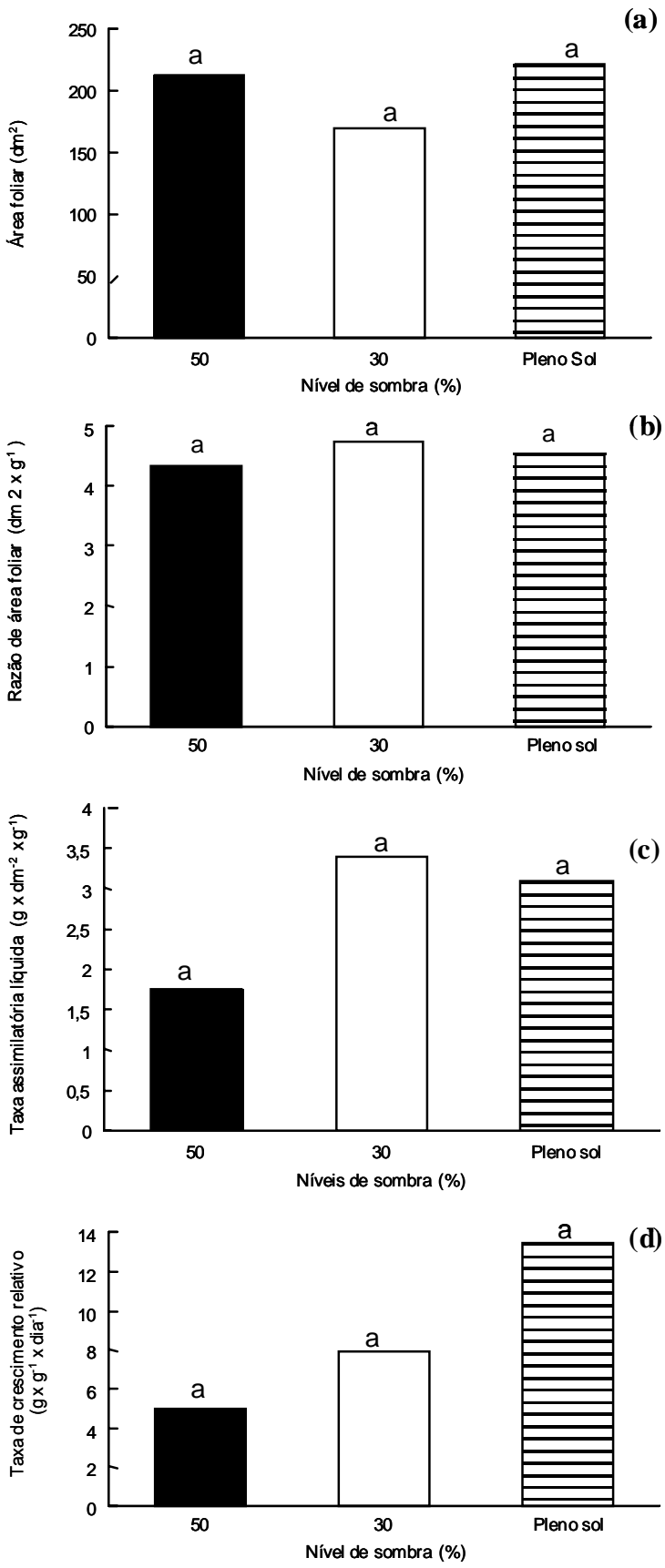

Figura 2 - Área foliar, razão de área foliar (RAF), taxa assimilatória líquida (TAL) etaxas de crescimento erelativo (TCR) das mudas de Bombacopsis glabra (Pasq.) A. Robyns (castanha-do-maranhão), crescendo em diferentes condições deluminosidade. UNIGRAN, Dourados-MS.

Figure 2 - Leaf area, leaf area ratio (FAR), net assimilating rate (NAR) and relatilve and growth rates (RGR) of Bombacopsis glabra (Pasq.) A. Robyns (castanha-domaranhão) saplings, developing under different Iuminosity conditions. Unigran, Dourados-MS. 
Quadro 2 - Massa seca, teores de clorofila total, a e b e relação clorofila a/b de mudas de Bombacopsis glabra (Pasq.) A. Robyns (castanha-do-maranhão) aos 124 dias após a emergência. UNIGRAN, Dourados-MS (média de três repetições)

Table 2 - Dry mass, total chlorophyl contents, $\boldsymbol{a}$ and $\boldsymbol{b}, \boldsymbol{a} / \boldsymbol{b}$ chlorophyl ratio from Bombacopsis glabra (Pasq.) A. Robyns (castanha-do-maranhão) saplings at 124 days after emergence. Unigran, Dourados MS. (average of three repetitions)

\begin{tabular}{|c|c|c|c|c|c|}
\hline $\begin{array}{c}\text { Nível de Sombra } \\
(\%)\end{array}$ & $\begin{array}{c}\text { Massa Seca da } \\
\text { Parte Aérea }\end{array}$ & Total & $\begin{array}{c}\text { Clorofila } \\
\mathrm{a}\end{array}$ & $\begin{array}{c}(\mathrm{mg} / \mathrm{g}) \\
\mathrm{b}\end{array}$ & $\mathrm{a} / \mathrm{b}$ \\
\hline 50 & $38,00 \mathrm{~b}$ & $1.434,34 \mathrm{a}$ & $848,67 \mathrm{a}$ & $585,67 \mathrm{a}$ & $1,45 \mathrm{~b}$ \\
30 & $42,50 \mathrm{ab}$ & $1.272,35 \mathrm{~b}$ & $806,35 \mathrm{a}$ & $466,00 \mathrm{a}$ & $1,73 \mathrm{a}$ \\
Pleno sol & $47,50 \mathrm{a}$ & $1.022,00 \mathrm{c}$ & $659,00 \mathrm{a}$ & $363,00 \mathrm{a}$ & $1,81 \mathrm{a}$ \\
\hline
\end{tabular}

Médias seguidas de mesma letra na coluna são estatisticamente iguais entre si pelo teste de Tukey, a 5\%.

O conteúdo de clorofila a e b não variou com o sombreamento, já o conteúdo de clorofila total foi maior em $50 \%$ de sombra e menor em pleno sol. A relação clorofila $\mathbf{a} / \mathbf{b}$ de castanha-do-maranhão foi significativamente menor nas plantas a $50 \%$ de sombreamento, provavelmente devido ao maior teor de clorofila $\mathbf{b}$ presente nessas mudas. $\mathrm{O}$ aumento da proporção de clorofila b é uma característica importante de ambientes sombreados, porque esta capta energia de outros comprimentos de onda e a transfere para a clorofila a, que efetivamente atua nas reações fotoquímicas da fotossíntese e representa um mecanismo de adaptação à condição de menor intensidade luminosa.

Vários autores têm relatado diminuição da razão clorofila $\mathbf{a}$ e $\mathbf{b}$ em folhas submetidas a menores intensidades luminosas (Ferraz \& Silva, 2001; Fontes \& Silva, 2001). A clorofila está sendo constantemente sintetizada e destruída em presença de luz (Kramer \& Koslowski, 1979).

\section{CONCLUSÃO}

A castanha-do-maranhão é uma espécie de alta capacidade de emergência e desenvolvimento inicial das mudas, tolerando bem o sombreamento de 30 e $50 \%$ e desenvolvendo-se satisfatoriamente a pleno sol.

Os níveis de luz estudados não afetaram a sobrevivência das mudas, o diâmetro do caule, a área foliar, a clorofila a e b, a TCR, a TAL e a RAF nos intervalos de tempo estudados. As mudas crescidas sob $50 \%$ de sombra apresentaram maior altura, maior clorofila total e menor relação $\mathbf{a} / \mathbf{b}$. Já as mudas crescidas em pleno sol apresentaram maior massa seca da parte aérea e a $50 \%$ de sombreamento, menor massa seca da parte aérea.

\section{AGRADECIMENTO}

Ao Sr. Paulo Zafra, pelo auxílio na condução do experimento no campo.

\section{REFERÊNCIAS BIBLIOGRÁFICAS}

ARNON, D. I. Cooper enzymes in isolated chloroplasts. Polyphenoloxidase in Beta vulgaris. Plant Physiology, v. 24 , n. 1 , p. $1-15,1949$.

BENINCASA, M. M. P. Análise de crescimento de plantas (noções básicas). Jaboticabal: FCAV-UNESP, 1988. $41 \mathrm{p}$.

BRASIL. Ministério da Agricultura e Reforma Agrária. Regras para análise de sementes. Brasília, 1993.

DIAS FILHO, M. B. Physiological response of Solanum crinitum Lam. to contrasting light environments. Pesquisa Agropecuária Brasileira, v. 32, p. 789-796, 1997.

ENGEL, V. L.; POGGIANI, F. Estudo da concentração de clorofila nas folhas e seu espectro de absorção de luz em função do sombreamento em mudas de quatro espécies florestais nativas. Revista Brasileira de Fisiologia Vegetal, v. 3, n. 1, p. 39-45, 1991.

FELFILI, J. M. et al. Comportamento de plântulas de Sclerolobium paniculatum Vog. var. rubiginosum (Tul.) Benth. sob diferentes níveis de sombreamento, em viveiro.

Revista Brasileira de Botânica, v. 22, n. 2, p. 13-17, 1999.

FERRAZ, K. K. F.; SILVA, D. M. Avaliação ecofisiológica do crescimento inicial de espécies florestais usadas na recuperação de áreas degradadas - II. Calliandra calothyrsus Meisn. In: CONGRESSO NACIONAL DE FISIOLOGIA, 8., 2001, Ilhéus-BA. CD-ROM. 6-087.

R. Árvore, Viçosa-MG, v.27, n.6, p.753-758, 2003 
FERREIRA, C. A . G. Recuperação de áreas degradadas. Informe Agropecuário, v. 21, n. 202, p. 127-130, 2000.

FONTES, R. V.; SILVA, D. M. Avaliação ecofisiológica do crescimento inicial de Piptadenia adiantoide (Spreng.) Macbr., espécie florestal usada na recuperação de áreas degradas. In: CONGRESSO NACIONAL DE FISIOLOGIA, 8., 2000, Ilhéus-BA. CD-ROM. 6-089.

GAJEGO, E. B. et al. Crescimento de plantas jovens de Maclura tinctoria e Hymenaea courbaril em diferentes condições de sombreamento. In: CONGRESSO

NACIONAL DE FISIOLOGIA, 8., 2001, Ilhéus-BA. CDROM.6-029.

GRONINGER, J. W. et al. Growth and photosynthetic responses of four Virginia Piedmont tree species to shade. Tree Physiology, v. 16, p. 773-778, 1996.

GRIME, J. P. Shade tolerance in flowering plants. Nature, v. 5006, n. 208, p. 161-163, 1965.

GRIME, J. P. Evidence for the existence of three primary srategies in plants and its relevance to ecological and evolutionary theory. The American Naturalist , v. 982, n. 3, p. 1169-1194, 1977.
KRAMER, T.; KOSLOWSKI, T. T. Physiology of woody plants. New York: Academic Press, 1979. 811 p.

LORENZI, H. Árvores brasileiras: manual e cultivo de plantas arbóreas nativas do Brasil. Nova Odessa: Plantarum, 1998. $352 \mathrm{p}$.

MONTEIRO, P. P. M.; RAMOS, F. A. Beneficiamento e quebra de dormência de sementes em cinco espécies florestais do cerrado. Revista Árvore, v. 21, n. 2, p. 169174, 1997.

POPINIGS , F. Fisiologia de sementes. Brasília: Agriplan, 1985. 285 p.

SCALON, S. P. Q.; ALVARENGA, A. A . Efeito do sombreamento sobre a formação de mudas de pau-pereira (Platycyamus regnelli Benth.). Revista Árvore, v. 17, n. 3, p. 265-270, 1993.

TINOCO, C.; VASQUEZ-YANES, C. Diferencias en poblaciones de Piper hispidus hajo condiciones de luz contratante en uma selva alta perenifolia. In: GOMEZPOMPA, A.; AMO, R.S. (Eds.) Investigaciones sobre la regeneration de selvas altas em Vera Cruz. Mexico. Alhambra Mexicana, 1985, T. 2, p. 267-281. 